ISSN 1981-416X

Licenciado sob uma Licença Creative Commons

(c) (i)

\title{
Pacto Nacional pelo Fortalecimento do Ensino Médio e o Programa Nacional do Livro Didático: aproximações necessárias
}

\author{
Brazilian National Pact for the Strengthening of Secondary \\ Education and the National Textbook Program: \\ necessary approaches
}

\begin{abstract}
Pacto Nacional por el Fortalecimiento de la Enseñanza Media y el Programa Nacional del Libro Didáctico: aproximaciones necesarias
\end{abstract}

\author{
Karine Bueno do Nascimento, Micheli Bordoli Amestoy, \\ Luiz Caldeira Brant de Tolentino-Neto*
}

Universidade Federal de Santa Maria (UFSM), Santa Maria, RS, Brasil

\section{Resumo}

Este artigo tem como objetivo investigar quais as influências do processo de formação docente no primeiro ano do Pacto Nacional pelo Fortalecimento do Ensino Médio na escolha do livro didático (LD) para o Ensino Médio. Realizou-se uma pesquisa qualitativa, do tipo estudo

\footnotetext{
"KBN: Mestre em Educação em Ciências, e-mail: karinebueno20@gmail.com MBA: Mestre em Educação em Ciências, e-mail: micheliamestoy@gmail.com LCBTN: Doutor em Educação, e-mail: Icaldeira@smail.ufsm.br
} 
de caso. A coleta de dados foi realizada em 2014 em um município do interior do Rio Grande do Sul, em uma escola de periferia. Dez professores de diferentes áreas do conhecimento e uma coordenadora/supervisora foram entrevistados por meio de um roteiro semiestruturado. O processo de escolha do LD caracterizou-se pelo individualismo, culminando na ausência de diálogos e reflexões entre todos os docentes. Porém, mesmo individualmente, notaram-se indícios positivos do Pacto na escolha dos LDs e no cotidiano dos docentes. Contudo, grandes mudanças, principalmente relacionadas a um "redesenho curricular", não se concretizam em ações isoladas; para que ocorram é preciso compreender a escola como unidade de múltiplas facetas, que necessitam problematizar, dialogar e refletir entre si.

Palavras-chave: Ensino Médio. Livro Didático. Currículo Escolar. Políticas Públicas.

\section{Abstract}

This article aims to investigate what influences does the teacher training process in the first year of the Brazilian National Pact for the Strengthening of Secondary Education have in the choice of textbooks (LD) for high school. We did a qualitative research, of a case study kind. Data collection was executed in 2014 out in a city in the interior of Rio Grande do Sul, in the outskirts. Ten teachers from different areas of knowledge and a coordinator/ supervisor were interviewed using a semi-structured screenplay. The process of choosing the textbook was characterized by individualism, culminating in the absence of dialogue and reflection among all teachers. But even individually, positive signs of the Pact for the Secondary Education were noted in the choice of textbook and in the daily lives of teachers. However, major changes, mainly referring to a "curriculum redesign" don't materialize in isolated actions. For this to occur it is necessary to understand the school as a unit of multiple facets, each of which needs questioning, discussing and reflection among each other.

Keywords: Secondary Education. Textbook. School Curriculum. Public Policy. 


\section{Resumen}

El objetivo de este artículo es investigar cuáles fueron las influencias del proceso de formación docente, durante el primer año del Pacto Nacional por el Fortalecimiento de la Enseñanza Media, en la elección del libro didáctico (LD) para la Enseñanza Media. Para esto, se realizó una investigación cualitativa, del tipo Estudio de Caso. El recogimiento de datos sucedió en 2014 en una ciudad situada en el interior del Rio Grande do Sul, específicamente, en una escuela de periferia. Diez profesores de distintas áreas del conocimiento y una coordinadora/supervisora fueron entrevistados por medio de una guía semiestructurada. El proceso de elección del LD se caracterizó por el individualismo, resultando en la ausencia de diálogos y reflexiones entre todos los docentes participantes. Aunque haya sucedido de modo individual, se notaron indicios positivos del Pacto en la elección de los LDs y en el cotidiano de los docentes. Sin embargo, grandes cambios, sobre todo relacionados a un 'rediseño curricular', no se concretizan en acciones aisladas, es decir, para que ocurran, es necesario comprender la escuela como unidad de múltiples facetas, que necesitan problematizar, dialogar y reflexionar entre sí.

Palabras clave: Enseñanza Media. Libro Didáctico. Currículo Escolar. Políticas Públicas.

\section{A docência no Brasil}

Constituir-se docente perpassa uma longa caminhada, a qual habitualmente começa na formação inicial e se desdobra com os acontecimentos ocorridos durante o exercício da profissão. Segundo Libâneo, Oliveira e Toschi (2012, p. 431) "o exercício profissional do professor compreende ao menos três atribuições: a docência, a atuação na organização e na gestão da escola e a produção de conhecimento pedagógico". Essas três atribuições articulam-se em torno da busca por uma identidade profissional, que segundo Nóvoa (2007, p. 16) está intrinsecamente ligada aos processos ocorridos durante toda sua caminhada na profissão, isto é, “a identidade não é um dado adquirido, não é uma propriedade, não é 
um produto. A identidade é um lugar de lutas e de conflitos, é um espaço de construção de maneiras ser de estar na profissão".

Nesta perspectiva, ser professor em meio à imensa pluralidade cultural, socioeconômica e étnico-racial que a população brasileira, não somente pela divisão geográfica de regiões e estados, mas também na mesma cidade, escola e sala de aula, exige que o professor desconstrua, reconstrua e construa metodologias didáticas adequadas de ensino para o contexto que está inserido, ampliando desta maneira não só suas opções didáticas, mas também perfazendo a história, o presente e o futuro da educação brasileira.

Segundo Libâneo, Oliveira e Toschi (2012, p. 495):

A organização do ensino depende de algumas condições imprescindíveis a ser propiciadas pela escola. Por exemplo: projeto pedagógico-curricular e plano de trabalho bem definidos, coerentes, com os quais os professores se sintam identificados; orientação metodológica segura por parte da coordenação pedagógica, implicando assistência permanente aos professores; formas de agrupamento de alunos, materiais de estudo e bons livros didáticos; sistema de avaliação da aprendizagem assumido por parte de todos os professores e formas de acompanhamento dos alunos com dificuldade; práticas de gestão participativa.

É neste contexto que surge a importância de uma formação inicial e continuada consistente e de qualidade. Neste sentido, nos últimos anos o Governo Federal tem investido em diversos programas que visam à formação dos professores; entre eles, destacamos o Pacto Nacional pelo Fortalecimento do Ensino Médio, que foi instituído em 2013 e será um dos focos desse estudo.

\section{Pacto Nacional pelo Fortalecimento do Ensino Médio (PNFEM)}

O PNFEM foi um programa instituído pelo Ministério da Educação pela Portaria Ministerial n ${ }^{0} 1.140$, de 22 de novembro de 2013. Nos ambientes escolares chamado somente de Pacto do Ensino Médio, ele surgiu 
como uma parceria entre Ministério da Educação (MEC) e secretarias estaduais e distrital de educação, que assumiram o compromisso de valorizar a formação continuada dos professores e coordenadores pedagógicos que atuam no ensino médio público de áreas urbanas e rurais (BRASIL, 2013b).

Além de contribuir, promover e valorizar a formação dos docentes e coordenadores do Ensino Médio, o pacto teve como objetivo rediscutir e atualizar as práticas docentes em conformidade com as Diretrizes Curriculares Nacionais do Ensino Médio (DCNEM), instituída pela Resolução CEB/CNE $\mathrm{n}^{\circ}$ 2, de 30 de janeiro de 2012 (BRASIL, 2012b), por intermédio do Programa Ensino Médio Inovador (ProEMI). O ProEMI foi criado em 2009, pela portaria $\mathrm{n}^{\circ}$ 971, de 9 de outubro de 2009, e tem como finalidade apoiar e fortalecer o desenvolvimento de propostas curriculares inovadoras, por meio de apoio técnico e financeiro para as escolas (BRASIL, 2013c).

A articulação entre estas políticas públicas (PNFEM, DCNEM e ProEMI) visa proporcionar um "redesenho curricular" para o ensino médio a nível nacional. Compreende-se como redesenho curricular, de acordo com os documentos orientadores (BRASIL, 2014a; 2014b), a formação integral dos educandos por meio da inserção de ações e atividades que tornem o currículo mais dinâmico. Pois, conforme as DCNEM (BRASIL, 2013a, p. 145), como está organizado atualmente o Ensino Médio brasileiro, "sua estrutura, seus conteúdos, bem como suas condições atuais, estão longe de atender às necessidades dos estudantes, tanto nos aspectos da formação para a cidadania como para o mundo do trabalho". Nesta perspectiva, o Estado pretende:

[...] induzir ao redesenho dos currículos do Ensino Médio, compreendendo que as ações propostas inicialmente serão incorporadas gradativamente ao currículo, ampliando o tempo na escola, na perspectiva da educação integral e a diversidade de práticas pedagógicas de modo que estas, de fato, qualifiquem os currículos das escolas de ensino médio (BRASIL, 2014a, p. 4).

A qualificação dos currículos do Ensino Médio perpassa o atendimento das necessidades e expectativas atuais dos estudantes, garantindo 
o direito à aprendizagem. Para que isto ocorra, 45 universidades públicas espalhadas pelo Brasil aderiram ao Pacto, e têm como responsabilidade promover a formação em seus estados. No Rio Grande do Sul, esta incumbência fica a cargo da Universidade Federal do Pampa, Pelotas, Rio Grande do Sul, Rio Grande e Santa Maria. A organização destas formações, de acordo com o art. $3^{\circ}$ que instituiu o PNFEM (BRASIL, 2013b), é da seguinte maneira:

Art. $3^{\circ}$ A formação continuada no âmbito do Pacto Nacional pelo Fortalecimento do Ensino Médio será organizada da seguinte forma: I - as instituições de ensino superior (IES) formadoras, definidas pelo MEC em articulação com as secretarias estaduais e distrital de Educação, são responsáveis pelo processo de formação; II - às IES compete a formação de formadores regionais;

III - os formadores regionais são responsáveis pela formação de orientadores de estudo; e

IV - os orientadores de estudo são responsáveis pela formação dos professores e coordenadores pedagógicos do ensino médio.

Para participar do Pacto, os professores das escolas estaduais do Ensino Médio deveriam estar atuando em sala de aula, e receberam bolsas para participar da formação, assim como os demais envolvidos ${ }^{1}$. A formação dos professores foi organizada em duas etapas, com duração de 100 horas cada , sendo 50 horas de atividades individuais, destinadas à leitura dos cadernos, bem como à elaboração de atividades propostas durante a formação. As outras 50 horas são designadas às atividades coletivas,

${ }^{1}$ De acordo com o art. 17 que institui o PNFEM (BRASIL, 2013), o FNDE pagará bolsa a todos os participantes do Pacto, a saber: I - R\$ 200,00 (duzentos reais) mensais, para o professor do ensino médio ou coordenador pedagógico do ensino médio; II - R\$ 765,00 (setecentos e sessenta e cinco reais), para o orientador de estudo; III - $\mathrm{R} \$ 1.100,00$ (mil e cem reais) para o professor formador regional do Pacto Nacional pelo Fortalecimento do Ensino Médio nos Estados e Distrito Federal; IV $\mathrm{R} \$ 1.100,00$ (mil e cem reais) para o formador da instituição de ensino superior; $V$ - $R \$ 1.200,00$ (mil e duzentos reais) para o supervisor; $\mathrm{VI}$ - $\mathrm{R} \$ 1.400,00$ (mil e quatrocentos reais) para o coordenadoradjunto da IES; e VII - R\$2.000,00 (dois mil reais) para o coordenador-geral da IES. 
tendo como objetivo o diálogo e reflexão, entre todos os docentes, sobre as leituras realizadas individualmente (BRASIL, 2014b).

Desta forma, a primeira etapa em âmbito nacional teve duração aproximada de sete meses (março a setembro de 2014) e ocorreu por meio dos Cadernos de Formação do Professor, disponíveis no site do Ministério da Educação, abordando os seguintes temas: Ensino Médio e formação humana integral, o jovem como sujeito do Ensino Médio, currículo no Ensino Médio, áreas de conhecimento e integração curricular, organização e gestão do trabalho pedagógico e avaliação do Ensino Médio. Já a segunda etapa de formação, iniciou em outubro de 2014, e está organizada em cinco Cadernos de Formação, os quais abordaram o tema organização do trabalho pedagógico e um estudo das áreas do conhecimento, a saber: ciências humanas, ciências da natureza, linguagens e matemática (BRASIL, 2014b).

Porém, independentemente de qual tenha sido o tema em questão, todos os cadernos visavam uma formação na qual os docentes sejam capazes de compreender as novas demandas do Ensino Médio brasileiro, a partir das novas DCNEM, e suas possibilidades de atuação frente a este cenário, culminando assim em um redesenho curricular (assim se espera). Acreditamos que um dos caminhos para que este redesenho curricular se concretize esteja vinculado aos materiais didáticos que os professores utilizam em suas aulas. Neste estudo, daremos destaque ao livro didático (LD).

\section{Programa Nacional do Livro Didático (PNLD)}

O PNLD foi criado em 1985 pelo decreto n ${ }^{\circ}$ 91.542, de 19 agosto de 1985, o qual entrou em vigor em 1986, no lugar do até então responsável pela política do LD no país, o Programa do Livro Didático para o Ensino Fundamental (BRASIL, 2012a). Porém, a história do LD no Brasil é anterior a esta data e, da década de 30 até os dias atuais, muitos foram os decretos, leis, normativas e portarias que fazem parte desta história. 
Exemplificá-las todas neste momento não seria oportuno, uma vez que utilizaria todo o espaço destinado para o artigo.

No entanto, cabe destacar que de acordo com Freitag, Costa e Motta (1997) a história do LD é uma mera sequência de medidas governamentais, as quais só são passíveis de compreensão se interpretadas em consonância com as mudanças ocorridas na sociedade brasileira, principalmente em relação a aspectos históricos do Estado Novo até a Nova República.

Deste modo, nos deteremos a partir da Constituição vigente no país (BRASIL, 1988), que decreta no art. 208 que o dever do Estado com a educação será efetivado mediante a garantia de diversos aspectos; dentre eles destacamos o inciso VII, que estipula: "atendimento ao educando, em todas as etapas da educação básica, por meio de programas suplementares de material didático-escolar [...]”. Nesta perspectiva, corroboramos com Zambon e Terrazzan (2013) e Cassiano (2007) ao entendermos que o PNLD configura-se como uma política de Estado, dado o seu período de existência, e principalmente pela amplitude do programa que visa atender toda a população estudantil brasileira matriculada em escola pública de educação básica.

Nesta perspectiva, muitas mudanças ocorreram no PNLD com a finalidade de adequar-se às demandas da educação brasileira; dentre elas, destacamos a avaliação pedagógica dos LD. Isto é, os livros distribuídos em âmbito nacional até 1996 não passavam por nenhum tipo de avaliação, pois o governo limitava-se somente à compra e distribuição do livro.

Segundo Cassiano (2007), o PNLD ganha rumos inéditos com a publicação do Plano Decenal de Educação Para Todos em 1993, em que o Estado considera o LD como um dos pilares para a melhoria da educação brasileira. Assim, no mesmo ano são definidos critérios para avaliação dos livros (BRASIL, 2012a), o que desencadeou a formação de um grupo para realizar essa avaliação. Conforme a mesma autora, o resultado demonstrou que o governo vinha investindo recursos públicos em livros desatualizados, preconceituosos e com erros conceituais.

Deste modo, em 1996, pela primeira vez, o governo, além de comprar e distribuir, também passa a avaliar pedagogicamente os livros inscritos para o PNLD. O fruto desta avaliação foi a publicação do primeiro Guia do 
Livro Didático (GLD), o qual tinha (e tem) como objetivo auxiliar os docentes no momento da escolha, assim, os livros que apresentaram erros conceituais, preconceito, discriminação, etc. foram excluídos do guia. Cabe destacar que este processo ocorre até hoje, e vem se aprimorando a cada edição.

Diante disso, o PNLD é considerado o mais antigo e maior programa mundial de distribuição de LD. Deste modo, a educação brasileira há muitos anos está permeada pelo uso dos LDs na educação básica. Nesta lógica, o LD se constituiu como uma importante ferramenta pedagógica, que segundo Lopes (2007, p. 208) pode ser compreendida como "uma versão didatizada do conhecimento para fins escolares". No entanto, mesmo o LD tendo um papel relevante no processo de ensino e aprendizagem dos alunos, este não deve ser o único material didático utilizado pelos docentes no âmbito escolar, como apontam Lajolo (1996), Bittencourt (2004), Choppin (2004) e Tagliani (2009). Para Lajolo (1996) todo material pode se tornar didático, depende somente da criatividade do professor.

Porém, segundo Horikawa e Jardilino (2010, p. 153) devido a inúmeros fatores, os docentes ficam restritos somente aos LDs como norteadores do currículo escolar:

O professor, submetido ao processo de desvalorização da instituição escolar, que se reflete nos baixos salários, nas péssimas condições de trabalho e no impedimento de investir em sua formação, vê sua atuação limitada a seguir, ano após anos, às prescrições de manuais didáticos.

Nesta perspectiva, os docentes veem o LD como um facilitador do seu trabalho. De acordo com os autores supracitados, cabe ao Estado proporcionar ações para reverter este quadro no Brasil, como, por exemplo, a formação continuada do docente, com o intuito de capacitá-lo "a avaliar e selecionar o material, mediante uma análise criteriosa das necessidades e possibilidades de aprendizagem da comunidade escolar em que atua" (HORIKAWA; JARDILINO, 2010, p. 158).

Deste modo, o presente artigo tem como escopo analisar como dois programas de âmbito nacional, um de formação de professores e outro 
de apoio didático, dialogam entre si. Especificamente o Pacto Nacional pelo Fortalecimento do Ensino Médio (PNFEM), e o mais antigo programa de suporte ao professor, o Programa Nacional do Livro Didático (PNLD). Neste sentido, pretende-se investigar quais as influências (neutras, positivas ou negativas) do primeiro ano de formação proporcionado pelo PNFEM no processo de escolha do Livro Didático (LD) para o Ensino Médio. Espera-se a partir deste estudo, contribuir com os debates em torno da formação continuada de professores e seus reflexos num provável "redesenho curricular".

\section{Delineamento metodológico}

Este estudo caracteriza-se como uma pesquisa qualitativa, do tipo estudo de caso. O primeiro encaminhamento para convidar as escolas a participarem dele foi verificar quantas escolas, no município em questão, possuem ensino médio. Foi contabilizado um universo de cinco escolas, todas estaduais. O segundo passo foi averiguar se a Secretaria Estadual de Educação do Rio Grande do Sul havia aderido ao PNLD, bem como se os docentes destas escolas participavam do Pacto Nacional pelo Fortalecimento do Ensino Médio, critérios essenciais para as instituições participarem do estudo.

Assim, após estes procedimentos, constatou-se que as cinco escolas estavam habilitadas a participar. Deste modo, após o contato com todas as escolas, realizado pessoalmente pelos autores deste estudo, somente uma das cinco escolas manifestou interesse. O motivo da não participação das demais escolas foi que não havia tempo para dispensar os docentes para participar da pesquisa ${ }^{2}$.

2 Zambon e Terrazzan (2013) tiveram uma experiência parecida ao convidar 27 escolas públicas de ensino médio a participarem de uma investigação sobre o processo de escolha do PNLD 2012. Isto é, das 27, somente 15 manifestaram interesse em participar. As demais instituições de ensino informaram que não recebiam retorno das pesquisas realizadas em suas escolas (3) e as outras (9), que não havia tempo para a realização das entrevistas propostas na investigação. 
Nesta perspectiva, participaram do estudo dez professores e uma (1) supervisora do Ensino Médio, que, depois de esclarecimento sobre os objetivos da pesquisa, assinaram o Termo de Consentimento Livre e Esclarecido (TCLE). Vale salientar que o total de professores nesta escola no Ensino Médio são 12; porém, foram excluídas duas docentes, pois estas não participaram do processo de escolha do Livro Didático, sendo uma professora de Educação Física (área em que, no momento da produção dos dados, o PNLD não tinha livros didáticos ) e outra que começou a atuar na escola após o processo de escolha. Isto significa que este estudo abrange todas as áreas de conhecimento que se é possível escolher livros didáticos.

A produção de dados foi feita por meio de entrevistas semiestruturadas realizadas individualmente na escola em que os docentes atuam, e cada entrevista teve duração em média de 20 minutos, os quais foram gravados e posteriormente transcritos. Para análise dos dados, optamos pela Análise de Conteúdo proposta por Bardin (2007).

\section{Perfil da comunidade escolar}

A escola em questão está localizada no interior do Rio Grande do Sul, em uma cidade de aproximadamente 60 mil habitantes. Fundada em 1996, em um bairro da periferia com nível socioeconômico baixo, condição social que se agravou com o decorrer dos anos, pelo fato de a comunidade (bairro) ser (re)conhecida como o centro de tráfico de drogas do município. Além disso, a maioria dos chefes de família (homens e mulheres) são desempregados, com escolaridade baixa e vivem em condições de moradias precárias. Neste sentido, entendemos que a comunidade escolar apresenta características de vulnerabilidade social.

A escola oferta para a comunidade as modalidades de Educação Infantil, Ensino Fundamental, Ensino Médio e Educação de Jovens e Adultos (EJA). Funciona nos turnos da manhã, tarde e noite. Com relação à infraestrutura escolar, segundo Soares Neto et al. (2013) a escola apresenta proficiência em infraestrutura adequada para um ambiente 
escolar ${ }^{3}$. Com relação aos recursos humanos, a escola atualmente tem 44 professores; destes, 12 atuam no ensino médio. Há ainda quatro supervisores pedagógicos (dois no ensino fundamental, um no Ensino Médio e um no EJA) e 25 funcionários. O número de alunos matriculados no total é de 750; destes, 110 pertencem ao Ensino Médio.

\section{Perfil dos docentes e supervisora}

A idade dos participantes da pesquisa varia de 30 a 62, com idade média de 47 anos. A maioria dos docentes, totalizando oito deles, assim como a supervisora pedagógica do ensino médio, é do gênero feminino, e o restante (dois docentes), do masculino. Segundo Böhm e Campos (2013, p. 69), é possível relacionar esta superioridade feminina com um pensamento histórico e cultural que "liga a mulher à maternidade, tornando-a perfeita para o ensino", assim como com a realidade salarial da docência, o que afasta os homens desta profissão.

A carga horária dos docentes varia de 40 a 60 horas semanais e todos também lecionam em escolas municipais no ensino fundamental. Com relação à formação dos docentes, elaboramos o quadro abaixo:

Quadro 1 - Formação acadêmica, área de atuação e experiência profissional dos professores entrevistados

(continua)

\begin{tabular}{|llllll|}
\hline Docente & Formação & Ministra aula de & $\begin{array}{l}\text { Tempo de } \\
\text { formação* }\end{array}$ & $\begin{array}{l}\text { Atuação } \\
\text { no ensino } \\
\text { médio* }\end{array}$ & $\begin{array}{l}\text { Vínculo nesta } \\
\text { escola* }\end{array}$ \\
\hline A & Matemática & $\begin{array}{l}\text { Matemática } \\
\text { e Biologia }\end{array}$ & 3 & 1 & 1 \\
\hline
\end{tabular}

3 De acordo com os autores, a proficiência em infraestrutura é medida em uma escala de quatro grandes níveis: elementar, básica, adequada e avançada. E ressaltam ainda que a maioria (51,3\%) das escolas estaduais do Brasil encontram-se na faixa de infraestrutura básica, com base nas informações do Censo Escolar da Educação Básica em 2011. Para maiores informações, consultar o trabalho dos autores. 
Quadro 1 - Formação acadêmica, área de atuação e experiência profissional dos professores entrevistados

(conclusão)

\begin{tabular}{|c|c|c|c|c|c|}
\hline Docente & Formação & Ministra aula de & $\begin{array}{l}\text { Tempo de } \\
\text { formação* }\end{array}$ & $\begin{array}{l}\text { Atuação } \\
\text { no ensino } \\
\text { médio* }\end{array}$ & $\begin{array}{l}\text { Vínculo nesta } \\
\text { escola* }\end{array}$ \\
\hline B & Química & Química e Física & 8 & 8 & 7 \\
\hline C & Matemática & $\begin{array}{l}\text { Matemática e } \\
\text { Biologia }\end{array}$ & 35 & 15 & 10 \\
\hline D & $\begin{array}{l}\text { Estudos } \\
\text { Sociais } \\
\text { Especialização } \\
\text { em História }\end{array}$ & $\begin{array}{l}\text { História, } \\
\text { Sociologia e } \\
\text { Filosofia }\end{array}$ & 20 & 6 & 6 \\
\hline$E$ & $\begin{array}{l}\text { Letras - } \\
\text { Português/ } \\
\text { Espanhol }\end{array}$ & $\begin{array}{l}\text { Seminário } \\
\text { Integrado e } \\
\text { Espanhol }\end{array}$ & 8 & 5 & 5 \\
\hline $\mathrm{F}$ & $\begin{array}{l}\text { Letras - } \\
\text { Português/ } \\
\text { Inglês }\end{array}$ & $\begin{array}{l}\text { Inglês e } \\
\text { Literatura }\end{array}$ & 7 & 2 & 2 \\
\hline G & $\begin{array}{l}\text { Letras - } \\
\text { Português/ } \\
\text { Inglês }\end{array}$ & $\begin{array}{l}\text { Português e } \\
\text { Literatura }\end{array}$ & 25 & 5 & 18 \\
\hline $\mathrm{H}$ & $\begin{array}{l}\text { Ciências } \\
\text { Biológicas }\end{array}$ & Biologia e Física & 3 & 3 & 3 \\
\hline I & $\begin{array}{l}\text { História e } \\
\text { Estudos } \\
\text { Sociais }\end{array}$ & Geografia & 18 & 10 & 18 \\
\hline J & Música & Artes & 2 & 2 & 2 \\
\hline $\begin{array}{l}\text { Supervi- } \\
\text { sora }\end{array}$ & $\begin{array}{l}\text { Ciências } \\
\text { Biológicas } \\
\text { Especialista } \\
\text { em Super- } \\
\text { visão Escolar }\end{array}$ & Supervisora & 25 & 10 & 8 \\
\hline
\end{tabular}

Fonte: Os autores (2014).

Nota: * - em anos.

A partir do quadro acima, percebe-se que nesta escola não há professores formados em Física e Geografia. Porém, isto não é exclusividade desta escola; diversos estudos, como o realizado por Ruiz, Ramos e 
Hingel (2007), demonstram a escassez de professores no Ensino Médio, principalmente nas disciplinas das Ciências Exatas e da Natureza.

\section{Organização escolar do processo de escolha do Livro Didático e do Pacto do Ensino Médio}

De acordo com Zambon e Terrazzan (2013), poucos são os trabalhos que investigam como ocorrem os processos de organização da escolha do LD por parte das equipes gestoras, pois a maioria tem como objeto de pesquisa os critérios utilizados pelos docentes para esta seleção. Diante disso, consideramos essencial contemplar neste estudo a organização por parte da gestão escolar e dos docentes para a escolha do LD no âmbito do PNLD para o ensino médio.

Nesta escola, o processo de organização para escolha do LD iniciou-se por parte da direção e supervisão, após a chegada da carta amare$1 a^{4}$. De acordo com as informações da supervisora, não foram organizadas reuniões pedagógicas voltadas ao PNLD 2015. A conduta adotada pela escola, com o auxílio da bibliotecária, foi de realizar cópias das orientações sobre a escolha do LD, as quais estão disponíveis no sítio eletrônico do FNDE e fazem parte do Guia, e distribuir individualmente aos docentes. Em posse destas orientações, os docentes tinham acesso, na biblioteca, a computadores para acessar o guia do LD e aos livros enviados pelas editoras, via correio, sendo que,

Este ano chegaram poucos materiais enviados pelas editoras, e dos poucos que chegaram, a maioria era somente folders, deste modo, a maioria das escolhas realizadas pelos professores foi baseada no guia [...] Assim, eles conversaram entre eles, mas bem informal, cada um em um horário que tinha disponivel,

\footnotetext{
${ }^{4} \mathrm{~A}$ carta amarela é um documento enviado para todas as escolas participantes do PNLD. Nela constam informações sobre o usuário e senha, que dão acesso a uma área restrita, onde serão registrados e gravados os livros didáticos escolhidos pelos docentes.
} 
ia na biblioteca e dava uma olhada e depois conversava com o colega de área e assim foi (SUPERVISORA ENSINO MÉDIO).

Os docentes, por sua vez, organizaram-se por área de formação para escolher os LD e tiveram em média 15 dias para proceder à escolha. Neste sentido, foi possível agrupar os docentes em três categorias. A primeira faz menção aos docentes que escolheram sozinhos os LD para o próximo triênio, pois ministram suas disciplinas sem o auxílio de outros professores (docentes B, D, F, I, J). A segunda categoria refere-se aos docentes que escolheram sozinhos os $\mathrm{LD}$, mas que compartilham a mesma disciplina com outros professores (A, B, C, H). Por fim, a terceira categoria refere-se a docentes que afirmaram não se recordar de terem participado da escolha do LD (E, G); porém, a supervisão relata que estas docentes participaram. Diante deste impasse, resolvemos não utilizar as respostas obtidas pelas docentes E e G.

A partir deste breve contexto das organizações para a escolha do LD, nota-se a influência negativa da ausência de organização de reuniões destinadas ao PNLD 2015, reunião esta recomendada pelo MEC por se compreender a importância do diálogo entre os participantes neste momento. Pois, independente de ministrarem suas disciplinas no Ensino Médio sozinhos ou não, os docentes não dialogaram entre si. E mesmo os que conversaram, como ilustrado pela fala da supervisora, o realizaram de forma informal, quando havia tempo disponível.

No entanto, esta é uma conduta inapropriada a ser adotada em um ambiente escolar, pois se espera que neste momento os docentes possam interagir, com tempo e ambiente adequado, destinado a reuniões pedagógicas que tenham como finalidade discussões amplas sobre temas que envolvem o processo de escolha do LD, pois, independente da área de conhecimento, todos atuam na mesma escola e ministram aulas para os mesmos alunos.

É possível detectar algumas consequências recorrentes da ausência de reuniões organizativas para a escolha dos LDs como, por exemplo, a carência dos docentes de uma explicação sobre a logística do PNLD, e de um estudo aprofundado sobre o Guia do LD. Estas consequências refletem-se na falta de conhecimentos, por parte dos docentes entrevistados, sobre o PNLD, uma vez que todos os professores participantes 
referiram-se ao PNLD como "um site" que a supervisão os orientou a acessar para realizar a escolha.

Embora isto seja algo muito debatido em diversas pesquisas que estudam o processo de escolha do Livro Didático - dentre elas destacamos Tolentino-Neto (2003), Tagliani (2009), Zambon e Terrazzan (2013) e Boton (2014) - , poucas medidas efetivas têm sido sugeridas por parte do MEC para reverter este quadro, a não ser as orientações que constam nos Guias, as quais, na maioria das vezes, nem os gestores escolares conhecem. Isso foi constatado por Zambon e Terrazzan (2013) ao realizarem um estudo com membros de equipes gestoras de escolas públicas da educação básica da cidade de Santa Maria/RS, em que muitos dos gestores ficaram sabendo da existência de um Guia do LD no momento em que foram questionados pelos os autores do estudo5.

Com relação à organização do Pacto do Ensino Médio na escola, neste estudo, abordaremos as prováveis influências do Pacto no processo de escolha do LD, somente da primeira etapa de formação, visto, que durante esta pesquisa, já se havia encerrado o processo desta primeira etapa e os docentes já haviam iniciado a segunda. Desta maneira, nos deteremos, brevemente, ao contexto da primeira etapa, na qual foi apresentado aos docentes um conjunto de temas fundamentados nas DCNEM, que subsidiaram a formação continuada dos professores e tinham como objetivo

[...] possibilitar a compreensão das diretrizes curriculares nacionais, criando-se um espaço para a reflexão coletiva sobre a prática docente e a importância da participação de todos os atores do processo educativo e na reescrita do Projeto Político Pedagógico da escola - PPP. Essas discussões deverão orientar o (re)desenho do currículo do Ensino Médio (BRASIL, 2014b, p. 8).

${ }^{5} \mathrm{O}$ fato de os gestores, assim como os professores, não conhecerem o guia do LD propicia um campo fértil de venda para as editoras, pois, ao enviarem suas coleções para as escolas, estas acabam escolhendo somente entre o material a que tiveram acesso pelas editoras. Este não foi o caso da escola investigada neste estudo; porém, esta é uma constância a nível nacional nos processos de escolha do LD, seja para o ensino fundamental ou médio. 
A formação na escola teve duração de seis meses (abril/setembro), totalizando 110 horas, sendo 60 horas de atividades coletivas e 50 horas individuais ${ }^{6}$. Durante as atividades, os professores participavam de um mesmo grupo de debate, independente da área de formação, como o recomendado. Cabe destacar que a supervisora do Ensino Médio, a qual participou deste estudo, também é a orientadora de estudo, pelo Pacto, nesta escola.

\title{
Influências do Pacto do Ensino Médio no Processo de escolha do Livro Didático
}

Sabendo da ausência das reuniões destinadas ao PNLD 2015, questionamos os docentes sobre se, no momento da escolha do LD, mesmo que individualmente, estes haviam levado em consideração a formação proporcionada pelo Pacto, a qual propõe uma reorganização curricular do Ensino Médio. Todos os docentes afirmaram que o Pacto influenciou no momento da escolha; deste modo, destacamos alguns trechos das entrevistas:

\begin{abstract}
[...] o pacto, ele faz a gente repensar as metodologias, então tu tem que mudar toda a tua maneira de dar aula. Acabei tendo uma outra visão, eu era mais preocupada somente com a aprendizagem, principalmente no ensino médio. E daí no pacto te faz pensar que também não é só isso, tem que fazer o contexto todo, como cidadão. Então, influencia na hora de escolher o livro, pois dependendo das atividades propostas nos livros, vai fazer com que os alunos pensem mais ou não, por isso escolhi um livro que apresentasse atividades de resolução de problemas relacionados com o cotidiano (DOCENTE A).
\end{abstract}

Influenciou, porque, com essas formações, teu crescimento é maior, tu aprende mais, tu se interessa mais. E se eu cresço em conhecimento, eu vou crescer também com a fonte de conhecimento, ou seja, que materiais vou utilizar para dar aula, sendo um deles o livro didático (DOCENTE B).

\footnotetext{
${ }^{6}$ Informação dada pela Supervisora participante deste estudo. Cabe destacar que esta informação demonstra uma situação atípica, uma vez que cada etapa, como descrito anteriormente, é de 100 horas e não 110 horas.
} 
As formações me proporcionaram ver um modo de ensinar mais atual, pois, como está posta, não existe mais como aprender desta maneira. Nós temos que estudar, e olhando como professora vai ser difícil, porque vou ter que me adaptar a uma outra realidade, mais moderna. Mas pensando em aluno, eu acho que pra eles vai ser mais prazeroso. Por isso que eu acho que escolher um livro adequado pra esta comunidade é importante, mas mais importante é utilizar outros materiais também (DOCENTE C).

O pacto me influenciou na minha prática, é uma outra visão. Na hora de planejar as tuas aulas, tu tem momentos que acha que está bem fora do contexto, que não é aquilo que tu deveria estar ministrando, mas na realidade é. Porque o pacto traz pra nós esta nova proposta, de ouvir o aluno; tu tem que trabalhar na realidade dele, mas nem por isso deixar de trazer conhecimento, mas agregar tudo isso. Mas isso não é fácil, tem que ter muito tempo de planejamento e criatividade. Por isso eu acho que escolher um livro que se aproxime ao máximo da realidade do aluno é essencial, foi isso que eu tentei fazer (DOCENTE D).

O pacto me proporcionou escolher um livro mais adequado à comunidade. Hoje, em si, aqui na escola, tudo o que a gente faz a gente visualiza a comunidade. Visualiza o público que nós temos, se nós visualizarmos outro público, nós vamos estar deixando eles de lado (DOCENTE H).

No pacto nós tivemos várias reuniões, foi muito bom, e esclareceu bastante, então me influenciou quando busco livros que atendem a necessidade da comunidade (DOCENTE I).

É possível notar, a partir dos relatos, indícios positivos do Pacto no processo de escolha do LD, mas também no cotidiano dos docentes. Percebe-se a pluralidade de implicações do Pacto nestes professores, quando relatam que após a formação continuada buscaram proporcionar atividades diferentes aos educandos, visando não somente a aprendizagem, mas também a cidadania, o rompimento com alguns padrões ultrapassados de ensinar e, principalmente, a libertação do LD como única fonte de material didático. 
Partindo do pressuposto das implicações positivas do Pacto no processo de escolha do LD, questionamos os docentes se houve ou não a troca das coleções didáticas ${ }^{7}$, se comparado com as escolhas do PNLD 2012. Todos os docentes afirmaram que trocaram as coleções, com exceção do professor que ministra a disciplina de Artes, o qual informou que é a primeira vez que há livros para escolha nesta disciplina.

Neste sentido, questionamos quais os motivos que levaram à mudança das coleções. A maioria dos docentes respondeu que trocaram as coleções pois as que utilizavam atualmente não estavam adequadas à realidade da comunidade, principalmente quando levados em consideração os estudos realizados no primeiro e segundo semestres pelo Pacto. Cabe destacar que, dos dez docentes que participaram deste estudo, quatro ainda não exerciam a docência nesta escola quando foram escolhidos os livros do Ensino Médio no PNLD 2012 (ver quadro 1) e argumentaram que os livros escolhidos pelos professores antecessores não correspondiam às necessidades dos alunos.

Escolhi um livro que eu já conhecia, porque não consigo trabalhar com este que a escola tem. Este que eu escolhi é do autor [...], ele é mais organizado, tem mais opções de atividades, fala um pouco mais sobre a história da matemática, o que os outros não falam. Os outros são muitos exercícios e repetitivos, só exercício e não atividades. Busquei algo que eu conheço e que fosse viável trabalhar nesta comunidade, que tornasse a disciplina mais atraente para os alunos (DOCENTE A).

Mudei porque a que está na escola agora não é adequada, é muito avançada para os alunos que nós temos, então quase não consigo utilizar o material. Escolhi uma que eu conheço, porque já trabalho com ela no ensino fundamental nesta escola, é bom pra dar continuidade (DOCENTE F).

A decorrência de mudar foi pelo que eu visualizei nos alunos. Porque nossos alunos são carentes e eles têm um pouco mais de dificuldade. Além disso, pelo que a gente vê o interesse do alunado diminuiu muito, então procurei

\footnotetext{
${ }^{7}$ Não nos deteremos nos nomes das coleções, pois nosso objetivo não é a divulgação das editoras.
} 
algo mais significativo pra eles, que torne um pouco mais interessante a disciplina, embora o livro não seja o único material que eu uso para tornar a aula mais atraente e dinâmica (DOCENTE $\mathrm{H}$ ).

Já os demais docentes atuavam na escola na época da escolha do PNLD 2012, sendo os responsáveis pelas escolhas passadas e atuais. Eles argumentaram que trocaram as coleções para tentar tornar suas aulas mais atraentes para os alunos e adequadas à realidade da comunidade escolar. Destacamos um trecho de uma das professoras entrevistadas:

Mudei porque, assim, querendo ou não o ensino médio está sofrendo certas modificações, bem como a gente tem percebido na prática há alguns anos, mas também pelos estudos que realizamos no Pacto. Por isso, eu escolhi um livro que envolva mais a tecnologia, pois assim posso trabalhar conteúdo aliado às necessidades atuais dos alunos (DOCENTE C).

Porém, duas docentes afirmaram que trocaram de coleção pois as que vinham utilizando não constavam no Guia,

Então, eu gostava muito da editora [...], mas este ano ela não constava entre os livros que eu podia escolher. Dai, ao entrar no site, encontrei um lançamento de uma editora, mas não lembro o nome, parecia muito bom o livro para esta escola, bem dinâmico, mas eu não pude escolher ele. Não pude escolher porque eu não conhecia o livro, porque era lançamento. Daí, para escolher uma nova coleção, eu fui pelos mais usados, porque daí eu já conheço os livros, e busquei um que fosse bom para esta escola (DOCENTE B).

Mudei. Mudei por que não encontrei a mesma que eu já vinha trabalhando. Por isso busquei um livro que envolvesse mais a pesquisa, porque as minhas disciplinas têm muita coisa pra ler, e os alunos não gostam muito, então é com a pesquisa que eu tento instigar a curiosidade deles, para que assim faça sentido o que eles estão lendo e fazendo (DOCENTE D).

A partir da fala de algumas professoras, nota-se ainda o receio em escolher livros que não conheçam, como destacado principalmente pela docente B. Segundo Tolentino-Neto (2003), os professores buscam livros que se adaptem ao seu estilo e à sua forma de atuar em sala de aula. Nesta 
perspectiva, não consideramos incorreto escolher LDs que já conheçam, desde que estejam adequados à comunidade e aos objetivos escolares da instituição em que atuam. Porém, é preciso que os docentes saiam de sua zona de conforto, no que se refere a sua prática didática, e ultrapassem a barreira de dependência do LD. Nesta perspectiva é preciso inovar.

\section{Algumas reflexões}

Os achados deste estudo apontam para uma não articulação das políticas públicas educacionais em âmbito escolar, quando se refere ao coletivo. Isto é, a gestão escolar não se propõe a promover a interlocução entre a formação proporcionada pelo Pacto e a política pública de material didático. Isto fica evidente quando não é ofertado aos docentes um ambiente que favoreça a dialogicidade e reflexividade entre todos eles, pois, como evidenciado a partir das respostas obtidas dos participantes neste estudo, todos escolheram os livros individualmente.

Ressaltamos que não estamos em nenhum momento indo contra a autonomia dos docentes para escolher os livros. No entanto, o que não é adequado, por exemplo, é ter três professores ministrando a mesma disciplina no Ensino Médio, um para cada ano, e somente um escolher os livros que serão utilizados por todos. Mesmo para aqueles docentes que ministram sua disciplina sem compartilhar com outro professor são importantes o diálogo e a interação, marcados pelo princípio de responsabilidade profissional e social.

Porém, mesmo com escolhas isoladas do LD, é possível constatar, pelo menos em discurso, que os docentes levaram em consideração a formação proporcionada pelo Pacto ao escolherem os LDs. Desta forma, consideramos que, individualmente, houve um entrelaçamento entre as formações proporcionadas pelo Pacto, as quais condizem as DCNEM, e a política pública do material didático, isto é, o PNLD.

No entanto, para garantir um "redesenho curricular" é necessário que as escolas ultrapassem algumas barreiras. Dentre elas destacamos 
a superação do entendimento das políticas públicas educacionais como isoladas, principalmente pelos gestores educacionais, pois o fio condutor de qualquer mudança são os sujeitos nela envolvidos. Não estamos dissertando somente em prol de um diálogo coletivo entre PNFEM e o PNLD, mas entre todas as políticas públicas educacionais, uma vez que todas apresentam um elo, que visam, pelo menos na teoria, promover uma educação de qualidade e equidade.

Acreditamos que, em uma perspectiva kuhniana, estamos no momento de troca de paradigmas na educação. É um momento de mudanças. É necessário mudar e construir novas alternativas para o Ensino. Buscar a ressignificação das metodologias e resgatar a ponte que existe entre o professor e a transposição didática dos conteúdos são etapas essenciais do processo de formação continuada dos professores. O investimento em formação continuada dos professores da Educação Básica é o início para uma conversa sobre reestruturação curricular. Os professores devem estar aptos a articular novas epistemologias com os Projetos Políticos Pedagógicos das escolas. Os programas dos Pactos federais são uma iniciativa muito bem-vinda para essa etapa do processo de reestruturação, ao passo que incorporam nas agendas escolares este debate.

Os resultados a médio e longo prazo virão se esses debates tiverem caráter crítico, coletivo e colaborativo. É preciso que todos os atores sociais envolvam-se nas discussões e atuem nas mudanças. Mudanças essas que devem ter o amparo do Estado não só no investimento em formação docente, mas também no bem-estar docente, com a diminuição de carga horária, infraestrutura adequada para exercer um trabalho diferenciado e a melhoria dos salários, que são alguns dos aspectos essenciais que poderão promover o início de um "redesenho curricular", dada a complexidade dessa questão, hoje, na educação. 


\section{Referências}

BARDIN, L. Análise de conteúdo. Lisboa: Edições 70, 2007.

BITTENCOURT, C. M. F. Em Foco: História, produção e memória do livro. Educação e Pesquisa, São Paulo, v. 30. n. 3, p. 471-473, set./dez. 2004.

BÖHM, B. C. de A.; CAMPOS, M. I. Atuação de professores homens na educação básica: um estado da arte sobre a produção acadêmica. Horizontes - Revista de Educação, v. 1, n. 1, p. 59-72, jan./jun. 2013.

BOTON, J. de M. O processo de escolha do livro didático por professores: a evolução do PNLD e seus efeitos no ensino de ciências. 2014. 95 f. Dissertação (Mestrado em Educação em Ciências) — Universidade Federal de Santa Maria, Santa Maria, 2014.

BRASIL. Constituição da República Federativa do Brasil de 1988. Diário Oficial [da] República Federativa do Brasil, Brasília, DF, 5 out. 1988. Disponível em: <http://www.planalto.gov.br/ccivil_03/constituicao/ConstituicaoCompilado. htm>. Acesso em: 15 maio 2014.

BRASIL. Fundo Nacional de Desenvolvimento da Educação. Histórico - Programa Nacional do Livro Didático. 2012a. Disponível em: <http://www.fnde.gov.br/component/k2/item/518-hist\%C3\%B3rico?Itemid=889\&highlight=YToxOntpOjA7 czoxMDoiaGlzdMOzcmljbyI7fQ==>. Acesso em: 7 jun. 2014.

BRASIL. Ministério da Educação. Diretrizes Curriculares Nacionais da Educação Básica. 2013a. 562 p.

BRASIL. Ministério da Educação. Documento Orientador - Programa Ensino Médio Inovador. 2014a. Disponível em: <http://pactoensinomedio.mec.gov.br/ images/pdf/doc_orientador_proemi_2014.pdf >. Acesso em: 10 nov. 2014.

BRASIL. Ministério da Educação. Documento Orientador - Pacto Nacional Pelo Fortalecimento do Ensino Médio. Brasília: MEC, 2014b. Disponível em: <http:// pactoensinomedio.mec.gov.br/images/pdf/pacto_fort_ensino_medio.pdf $\rangle$. Acesso em: 10 nov. 2014. 
BRASIL. Ministério da Educação. Portaria n 1.140, de 22 de novembro de 2013. Pacto Nacional pelo Fortalecimento do Ensino Médio. Diário Oficial [da] República Federativa do Brasil, Brasília, DF, 9 dez. 2013b. Seção 1, p. 24-25.

BRASIL. Ministério da Educação. Programa Ensino Médio Inovador. Portaria n ${ }^{\circ}$ 971, de 9 de outubro de 2009. Diário Oficial [da] República Federativa do Brasil, Brasília, DF, 13 out. 2013c. Seção 1, p. 52.

BRASIL. Resolução CNE/CEB n 2, de 30 de janeiro de 2012. Define Diretrizes Curriculares Nacionais para o Ensino Médio. Diário Oficial [da] República Federativa do Brasil, Brasília, DF, 31 jan. 2012b. Seção 1, p. 20.

CASSIANO, C. C. de F. O Mercado do livro didático no Brasil: da criação do Programa Nacional do Livro Didático à entrada do capital internacional espanhol (19852007). 2007. 252 f. Tese (Doutorado em Educação) — Pontifícia Universidade Católica de São Paulo, São Paulo, 2007.

CHOPPIN, A. História dos livros e das edições didáticas: sobre o estado da arte. Educação e Pesquisa, São Paulo, v. 30. n. 3, p. 549-566, set./dez. 2004.

FREITAG, B.; COSTA, W. F.; MOTTA, V. R. O livro didático em questão. 3. ed. São Paulo: Cortez, 1997.

HORIKAMA, A. Y.; JARDILINO, J. L. A formação de professores e o livro didático: avaliação e controle dos saberes escolares. Revista Lusófona de Educação, v. 15, p. 147-162, 2010.

LAJOLO, M. Livro didático: um (quase) manual de usuário. Em Aberto, Brasília, v. 16, n. 69, jan./mar. 1996.

LIBÂNEO, J. C.; OLIVEIRA, J. F.; TOSCHI, M. S. Educação escolar: políticas, estrutura e organização. 10. ed. São Paulo: Cortez, 2012.

LOPES, A. C. Currículo e Epistemologia. Ijuí: Unijuí, 2007.

NÓVOA, A. Os professores e as histórias da sua vida. In: NÓVOA, A. (Coord). Vida de professores. 2. ed. Porto: Porto, 2007. p. 11-30. 
RUIZ, A. I.; RAMOS, M. N.; HINGEL, M. Escassez de professores no Ensino Médio: propostas estruturais e emergenciais. 2007. Relatório produzido pela comissão especial instituída para estudar medidas que visem a superar o déficit docente do Ensino Médio. Disponível em: <http://portal.mec.gov.br/cne/arquivos/pdf/ escassez1.pdf $>$. Acesso em: 15 nov. 2014.

SOARES NETO, J. J. et al. Uma escala para medir a infraestrutura escolar. Estudos de Avaliação Educacional, v. 24, n. 54, p. 78-99, jan./abr. 2013.

TAGLIANI, D. C. O processo de escolha do livro didático de língua portuguesa. Linguagem em (Dis)curso, Palhoça, v. 9, n. 2, p. 303-320, maio/ago. 2009.

TOLENTINO-NETO, L. C. B de. O Processo de Escolha do Livro Didático de Ciências por professores de $1^{a} a 4^{a}$ séries. 2003. 103 f. Dissertação (Mestrado em Educação) — Faculdade de Educação, Universidade de São Paulo, São Paulo, 2003.

ZAMBON, L. B.; TERRAZZAN, E. A. Política de material didático no Brasil: organização dos processos de escolha de livros didáticos em escolas públicas de educação básica. Revista Brasileira de Estudos Pedagógicos (Online), v. 94, n. 237, p. 585-602, maio/ago. 2013.

Recebido: 30/04/2018

Received: 04/30/2018

Recibido: 30/04/2018

Aprovado: 25/05/2018 Approved: 05/25/2018 Aprobado: 25/05/2018 